\title{
Coaching your thought: A Sapirian look
}

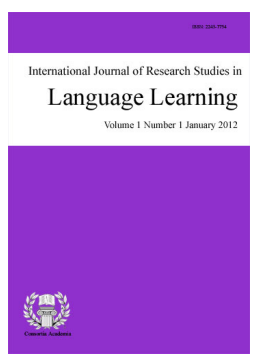

ISSN: $2243-7754$ Online ISSN: 2243-7762

OPEN ACCESS

Department of English, Science and Research Branch, Islamic Azad University, Tehran, Iran (Mojtabateimourtash@gmail.com)

$\begin{array}{lll}\text { Received: } 15 \text { August } 2015 & \text { Revised: } 20 \text { September } 2015 \quad \text { Accepted: } 23 \text { October } 2015\end{array}$

\section{Abstract}

That the language shapes the way we think has been fueled in large part by the observation that different languages talk about the world differently. Concerning language-thought relationship, there are several versions. One common version, most often associated with Sapir (1921), is that differences between languages lead to differences in thought. Henceforth, the present paper, interested in a relativist perspective regarding thought-language relationship, is in an attempt at mulling over the current debates on this very issue.

Keywords: discourse; language; thought; coaching thought; mould and cloak theories; SLA; bilingual; abstractness; Kaplan's Discourse Structures interpretation; Sapir-Whorf's linguistic relativity; ecological perspectives 


\section{Coaching your thought: A Sapirian look}

\section{Introduction}

Undeniably, "no words are oftener on our lips than thinking and thought" (Dewey, 1910, p. 1). Thinking is considered as one of the hallmarks of the human species. Understanding the nature of thought has been an important and central issue for our understanding of reality. As Loar (2006) claims, the noun 'thought' is ambiguous. It can mean what a person thinks; that is, the contents of acts of thinking - a proposition. In this case, talking about thought is philosophical, but it can also mean an act of thinking. In this sense, thought can be viewed as a psychological trend.

Whether thought and language are fused or segregated was always a matter of issue among philosophers. If we come to this probable conclusion that language and thoughts are segregated; then we should pursue an answer to the thesis that which one precedes the other. In contrast, viewing that thought and language are fused is inspired by a reductionist perspective in philosophy. Among the earlier philosophers who were interested in the language-thought relationship was Benveniste (1971) who attempts to reduce thought to language in his metaphor of thought as a container which cannot be separated from its content. In other words, Benveniste's argument is that language precedes thought, shapes it, and cannot be separated from it as the unconscious is structured by a language, a rather Lacanian move.

\section{Mould- vs. cloak theories}

Without a doubt, "every philosophical problem is a linguistic puzzle" (Slobin, 2005, p. 17), and language-thought issue is not an exception. Generally speaking, there are two extreme positions concerning the relationship between thought and language that are commonly referred to as 'mould theories' and 'cloak theories' (Bruner, Goodnow, \& Austin, 1956, cited in Chandler, 1994, p. 1). Cloak theories adopted by the extreme universalism (Chandler, 1994), represent the view that language is a cloak or dress conforming to the customary categories of thought of its speakers. In contrast, mould theories, such as Sapir-Whorf theory, represent language metaphorically as a mould in terms of which thought categories are cast (Bruner et al. 1956). In fact, considering language as a dress of thought implies that the same thought can be expressed in various ways (Bruner et al, 1956). That is, it is the thought that customizes language. Unfortunately, none of these camps has left us with solvable issue of how language and thought have an influence on each other.

Believers in cross-linguistic differences counter that everyone does not attend to the same things. If everyone did, one might think it would be easy to speak other languages. Henceforth, differences between languages, such as English and Persian, lead to differences in thought, which are undeniably devoted and rooted in cultural axe that cannot be meshed from both languages and thoughts of one particular group of people. As it is stated in the Holy Quran:

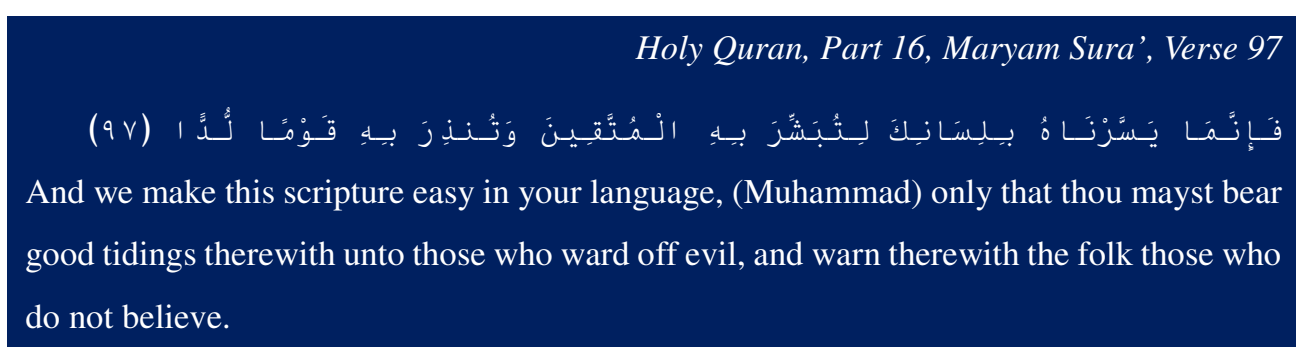


The culture axe plays a significant role as a determiner in coaching the thoughts of its practitioners, in such a way, thoughts cannot be defined such crystal-clear one single phenomenon. In simple terms, thought and culture are interwoven and best regarded as the two sides of a single coin that is why culture is simply what and how a group of people think.

\section{SLA stance}

Unfortunately, second language acquisition (SLA) is not an easy task; it requires paying attention to not only linguistic but also communicative components. SLA means more than mastering the linguistic components (i.e., words, structures, and sounds). According to Afghari and Karimnia (2007), "to see the world as native speakers of that language see it" (p. 250). In fact, learning a language entails understanding their language of the mind. And this is not attainable unless one gets to a thorough understanding of diverse cultures since each culture is unique on its own. Moreover, using a dazzling array of languages, human beings communicate. Do the language we speak shape the way we see the world, the way we think, and the way we live? These questions touch upon nearly all of the major controversies in the study of the language-thought relationship.

Scores of philosophers, anthropologists, linguists, and psychologists are interested in the very question whether language influences thought. Seemingly, "languages force us to attend to certain aspects of our experience by making them grammatically obligatory. Therefore, speakers of different languages may be biased to attend to and encode different aspects of their experience while speaking" (Boroditsky, 2001, p. 2). Encoding and decoding processes are the manifestation of the relationship between thought and language, in other words, coaching thought through the speech acts as language devices.

\section{Bilingual challenges}

Undeniably, "Saussure's idea that the language system segments the reality into conceptual chunks, thereby imposing categories by which people perceive and understand the world" (Birjandi \& Sabah, 2012, p. 51) has become the bone of contention among scholars. From Sapir (1921), who insists on the influence of language on thought, to Chomsky (1983) who is in search for an independent epistemology between thought and language, there has been a rationalist-relativist tension that has not yet been dissolved. However, the present paper is not an attempt to argue for the precedence of language or thought, but is keen on knowing what makes bilinguals face speaking difficulties in authentic circumstances and the required strategies in getting along with its ups-and-downs. Is it due to the manner he/she thinks or other factors get involved? Is it plausible to claim that language, at any case, has an impact on thought?

Slobin (1996) raises the issue that language may influence thought during "thinking for speaking". However the term influence can be a bewildering one in such case. By putting the idea in simple terms, the "coaching role" for both, language and thought, is a rule of thumb. Slobin maintains that speaking in any language entails arranging thoughts based on the categories of the very language. Indeed, to him "language is a suggestion based on a very limited notation system.... But, 'thinking for speaking' is the level at which thought is forced into that schematic expression that a particular language gives you" (p. 15).

In this regard, Athanasopoulos (2011, cited in Trefers-Daller, 2012) outlines several linguistic and socio-cultural factors that probably affect bilingual thinking: (a) specific language proficiency, (b) general language proficiency, (c) age of language acquisition, (d) amount of language use, (e) interactional setting, and (f) length of staying in L2 speaking community. 


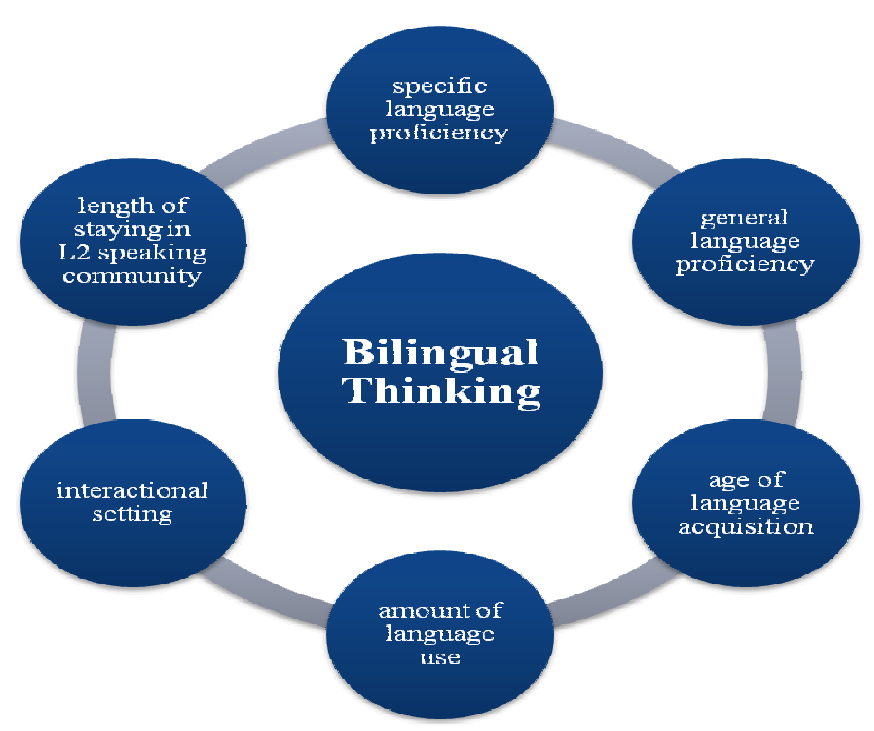

\section{Abstractness and Kaplan's interpretation}

Moreover, the amount of time, an individual spends on thinking for speaking depends on the word level of abstractness. Along the same vein, Boroditsky (2001) goes on to hold that "language is most powerful in determining thought for domains that are more abstract, that is, ones that are not so reliant on sensory experience" (p. 19).

More specifically, scholars (e.g., Lay, 1982) argue that individuals with more developed L1 literacy skills perform better in second language writing. However, Kaplan (1972) and Conner (1996) contend that language and writing are cultural phenomenon and, therefore, each language has rhetorical conventions unique to it which makes one's L1 writing different and distinct from his/her L2 writing. Put differently, to convey realities of the world, languages make use of a variety of pragmalinguisitc resources. Kaplan (1972), in this regard, contend that English text was characteristically linear and hierarchical due to the fact that English speakers tend to be direct and straightforward in speech and writing. Thus, English speakers use direct expressions and patterns, while oriental people prefer to use indirect patterns. Kaplan's cultural thought patterns can be illustrated by the following patterns:

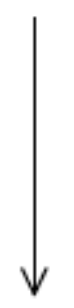

(a)

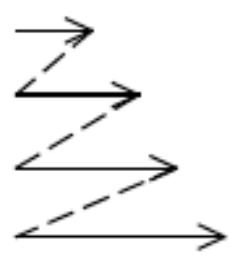

(b)

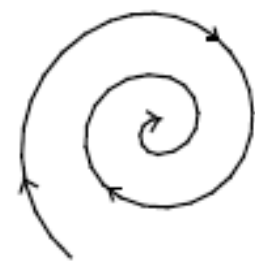

(c)

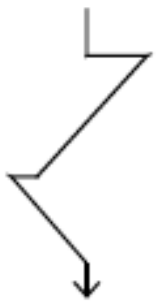

(d)

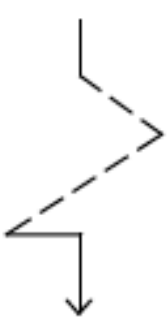

(e)

(a) English, (b) Semitic (Hebrew and Arabic), (c) Oriental, (d) Roman, (e) Russian Discourse Structures by Kaplan (1972)

Kaplan's contrastive rhetoric argues how a person's first language and culture coach his or her writing in a second language or culture. In fact, the linguistic and cultural patterns of learners' mother tongue might transfer into their writing not only at the word and sentence level but also at the discourse level. 
European Americans, for instance, tend to speak very directly about certain things. They tends to rely heavily on logic and technical information rather than allusion, metaphor, or other more creative or emotional styles of persuasion. Indeed, good communication is believed to be linear: the speaker should move through their points in a straight, logical line, with an explicitly stated conclusion (Elliott, 2010). Nevertheless, this style of communication may be viewed by other cultural groups inappropriate.

In this regard, Delen and Tavil (2010) also contend that when learning L2, most pupils appeal to their L1 to come up with different speech acts. This may result in miscommunication. Indeed, there are a variety of factors that affect one's learning. Accordingly, Moghadam (2012) asserts that the quality of communications is determined by mutual constraints which exist among interlocutors. As it is stated in the Holy Quran:

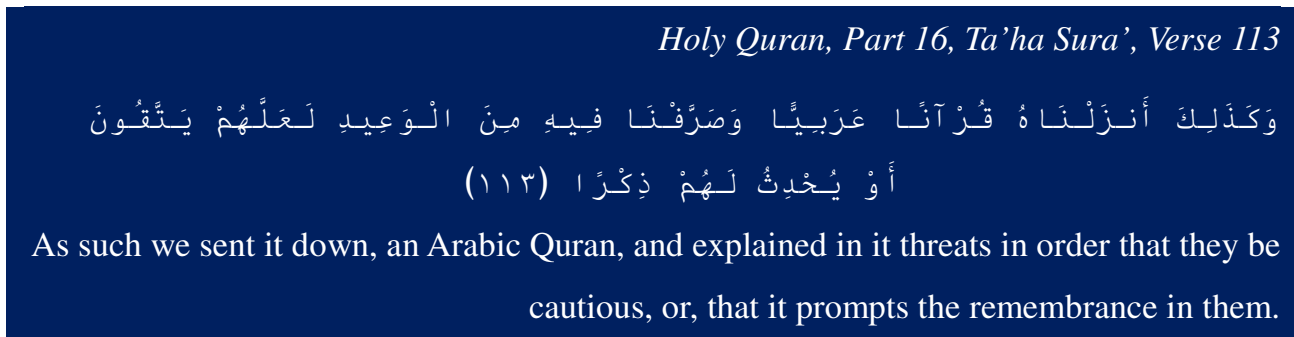

Wolfson (1989) argues that L1 speaker of what she calls rules of speaking is mostly conscious. In contrast, L2 speakers do not have reliable information regarding the ways in which they use the language. Henceforth, they switch from one language to another without being aware of it. Furthermore, they cannot accurately report their use of these languages. Native speakers, as to Wolfson, D'Amico-Reisner, and Huber (1983), often report that they typically use or do not use specific forms; however, their description does not match reality.

\section{Strong and weak versions of Sapir-Whorf's linguistic relativity}

Plausibly, Kaplan's contrastive rhetoric is anchored in Sapir-Whorf's linguistic relativity. To Sapir, "speakers of different languages perceive and express the world around them differently because of the ways in which languages influences a person's thinking" (Wintergerst \& McVeigh, 2011, p. 28). In effect, since languages vary in grammatical structures, linguistic categories and many other ways, Sapir and Whorf concluded that the speakers of different languages have different ways of viewing of the world. As it is stated in the Holy Quran:

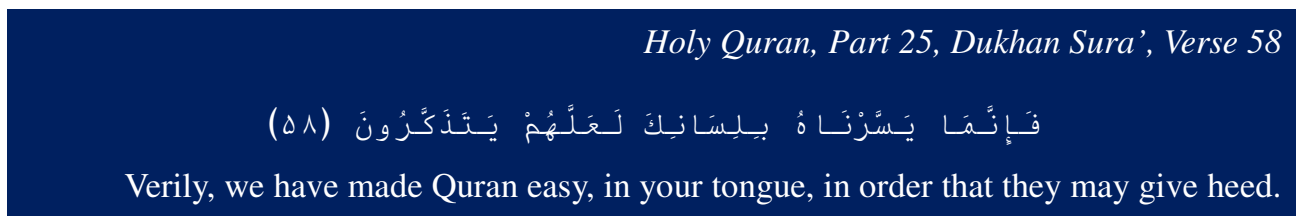

The strong version of Sapir-Whorf hypothesis Sapir contends that languages determine thought. Sapir believes that we are prisoners of our language and the way we think is determined by our language. In contrast, the weak version of the very hypothesis, readily more accepted (DeCapua \& Wintegrest, 2004), holds that language influences thought but not determines it, in better words, languages coach thoughts exclusively. In a sense, Sapir-Whorf theory represents language metaphorically as a mould in terms of which thought categories are cast. According to Sapir (1921), in providing an answer to the question whether thought is possible without speech, puts forth, "language and thoughts are not strictly coterminous" (p. 14). Put differently, language is 
Teimourtash, M., Shakouri, N., \& Teimourtash, M.

primarily a pre-rational function; it works up to the thought that is latent in. To Sapir, language determines thought.

\section{Williams and Burden's ecological perspectives of language}

However, how a person speaks is under the influence of a variety of factors. Accordingly, Williams and Burden (1997) refer to ecological perspectives of language. Williams and Burden's ecological perspectives of language is sub-parted into four factors: Microsystem, Mesosystem, Ecosystem, and Macrosystem. Microsystem is the outest layer closest to the child and contains the structures which the child has direct contact with. In effect, the very layer encompasses the interactions that the child has with his intermediate surroundings including parents. Mesosystem, in contrast, connects two or more systems in which children together with their family live, for example the relation between the child's teachers and parents. Ecosystem is also defined as the network of interactions between organisms and their environment. Finally, macrosystem placed at the outermost layer takes into account the entire culture of the society. Moghadam (2012) contends that Williams and Burden's (1997) model is similar to the structure of an onion holding that "human beings have interactions with cultural and societal layers covering them..., the learner is placed at the center of an onion-like structure. Therefore, individuals may have different styles and strategies when talking together since they are from different status" (p. 112).

Ecologically, the emphasis in SLA theories has shifted in recent years from grammatical approach to interactive approach. In fact, what makes people face difficulties in understanding each other is not grammatical competence, but communicative one. The notion of communicative competence was earlier introduced by Hymes (1972) who used it to describe the underlying knowledge required to use language effectively and appropriately in context.

Nevertheless, what Hymes stated refers to the development of communicative competence in L1 (Blum-Kulka, 1982). From an SLA perspective the question is how we experience it in another language. Hymes (1972) asserts that there are significant differences not only in the structure of languages but also in their use. Elsewhere, Hymes (1971, cited in Warschauer \& Kern, 2000) contends "language is not just a private, constructed in the head affair, but rather a socially constructed phenomenon" (p. 4). Hymes's (1972) communicative competence in response to Chomsky's mentalistic concept of linguistic competence insists on the social appropriateness of language remarking, that there are rules of use without which the rules of grammar will be useless. For Hymes, syntax and language forms are best understood not as autonomous, a contextual structures, but rather as meaning resources used in conventional ways in particular speech communities. In much the same way, Warschauer and Kern (2000) put that "grammaticality was not separable from social acceptability, nor was cognition separable from communication" (p. 5).

As to Blum-Kulka (1982), the difficulties L2 learners face in achieving communicative competence in L2 might be deeply rooted in the "differences between language and culture in various aspects of speech-act realizations" (p. 6). Similarly, Blum-Kulka counts four issues that these differences can be justified: (a) social appropriateness, (b) linguistic realization, (c) marking, and (d) mitigating and aggravating.

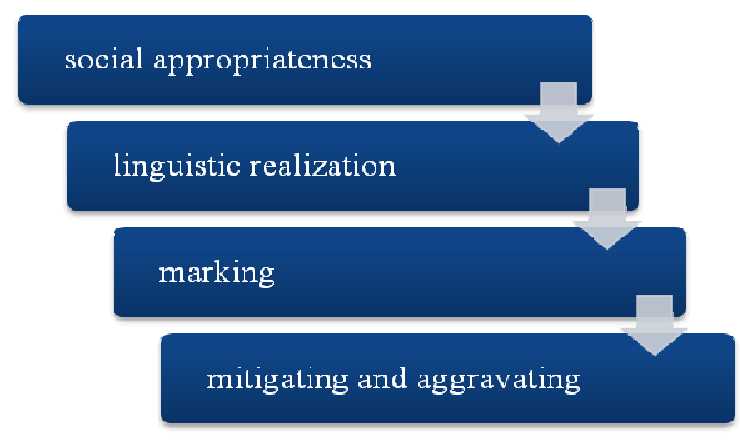


Social appropriateness implies the employment of a set of social rules that determine when to speak or when to be silent. Linguistic realization, also, refers to the fact that though languages possess different forms, they are equipped with equivalent, idiomatic standard forms for the performance of indirect speech-acts. Marking refers to the specific means, either translatable or not, whereby speakers can signal to their hearers the intended illocutionary force of their utterances. And finally, mitigating as to Fraser (1978) is defined as the intentional softening or erasing of force of the message. Aggravating, in contrast, refers to the intentional stressing on a produced message.

Practically speaking, lack of knowledge and proficiency in pragmatic aspects of language may result in breakdowns in communications (Moghadam, 2012). Indeed, since people have interactions in society, there is a need to use language in different situations appropriately. In the EFL context, learners need to be exposed to sufficient amount of input so that they could grasp of pragmatics. Appreciating the concept of pragmatics, the paper feels a need to draw a distinction between pragmalinguistics and sociopragmatics. As to Richards and Schmidt (2010), pragmalinguistics, as interface between linguistics and pragmatics, focuses "on the linguistic means used to accomplish pragmatic ends", while sociopragmatics entails "the relationship between social factors and pragmatics". In the former, we are concerned with how we make a function; whereas in the latter, we need to know in what circumstances we have to make a compliment, for instance.

In reality, the simplest operations in a given language are culturally dependent (Afghari \& Karimnia, 2007). In this regard White (1993, cited in Afghari \& Karimnia, 2007) asserts that in situations where native speakers of Japanese misused the word of PLEASE, the people experience conflicting signals, tension, offence, confusion, public misinterpretation that lead to pragmalinguistic failure.

\section{Conclusion}

The language-thought relationship is not generally posed in the hope that someone will come up with a definite answer. What fails to direct unanimity among scholars was the very tension between the two schools of rationalism and relativism that has not yet dissolved. What prods Pinker (1994) to dedicate a chapter to the absurdity of Whorfian relativism is deeply rooted in the very tension between the two schools of philosophy (i.e., rationalism and relativism). Indeed, what put the rationalists and relativists in contrast is the notion of translatability. Rationalists, and among them universalists, do claim that whatever we say in one language can be translated into another. However, cross-linguistic differences reveal that the culture and environment where human beings are raised determines their thought patterns. And language and culture are not separate. In a sense, the type of input, for instance, affects not only the brain but also the thought. In the same way, language affects thought by creating new concepts and these concepts emerge through exposure to word. As languages possess different lexicons; then they come to possess different concepts.

\section{References}

Afghari, A., \& Karimnia, A. (2007). A contrastive study of four cultural differences in everyday conversation between English and Persian. Intercultural Communication Studies, 16(1), 243-250.

Benveniste, E. (1971). Problems of general linguistics. Paris: Editions Gallimard.

Birjandi, P., \& Sabah, S. (2012). A review of the language thought debate: Multivariant perspectives. BRAIN. Broad Research in Artificial Intelligence and Neuroscience, 3(1), 50-62.

Bloom, P., \& Keil, F. C. (2001). Thinking through language. Mind \& Language, 16(4), 351-367. http://dx.doi.org/10.1111/1468-0017.00175

Blum-Kulka, S. (1982). Learning how to say what you mean in a second language: A study of speech act performance of learners of Hebrew as a second language. Applied Linguistics, 3, 29-59. http://dx.doi.org/10.1093/applin/3.1.29

Boroditsky, L. (2001). Does language shape thought? Mandarian and English speakers' conception if time. Cognitive Psychology, 43, 1-22. http://dx.doi.org/10.1006/cogp.2001.0748 
Teimourtash, M., Shakouri, N., \& Teimourtash, M.

Chandler, D. (1994). The Sapir-Whorf hypothesis. Retrieved from http://www.aber.ac.uk/media/Document

Connor, U. (1996). Contrastive rhetoric: Cross-cultural aspects of second language writing. Cambridge: Cambridge University Press. http://dx.doi.org/10.1017/CBO9781139524599

DeCapua, A., \& Wintergerst, A. C. (2004). Crossing cultures in the language classroom. Ann Arbor: University of Michigan Press.

Delen, B., \& Tavil, Z. M. (2010). Evaluation of four course books in terms of three speech acts: Requests, refusals and complaints. Social and Behavioral Sciences, 9, 692-697.

Dewey, J. (1910). How we think: A restatement of the relation of reflective thinking to the education process. Boston: Heath. http://dx.doi.org/10.1037/10903-000

Elliott, C. E. (2010). Cross-cultural Styles. Retrieved from http://www.Awesomelibrary.org/multiculturaltoolkit-patterns.html

Fraser, B. (1978). Acquiring social competence in a second language. RELC Journal, 9(2), 1-26. http://dx.doi.org/10.1177/003368827800900201

Holy Quran, Part 16, Maryam Sura', Verse 97.

Holy Quran, Part 16, Ta'ha Sura', Verse 113.

Holy Quran, Part 25, Dukhan Sura', Verse 58.

Hymes, D. H. (1972). On communicative competence. In J. B. Pride \& J. Holmes (Eds.), Sociolinguistics: Selected readings (pp. 269-293). London: Penguin Books.

Kaplan, R. B. (1972). Contrastive rhetoric and second language learning: Notes toward a theory of contrastive rhetoric. In A. C. Purves (Ed.), Writing across languages and cultures: Issues in contrastive rhetoric (pp. 257-304). Newbury Park, CA: Sage.

Lay, N. (1982). Composing processes of adult ESL learners. TESOL Quarterly, 16(3), 406.

Loar, B. (2006). Language, thought, and meaning. In M. Devitt \& H. Richard (Eds.), The Blackwell guide to the philosophy of language (pp. 77-90). London: Blackwell Publishing. http://dx.doi.org/10.1002/9780470757031.ch4

Moghadam, M. M. (2012). Discourse structures of condolence speech act. Journal of English Language Teaching and Learning, 10, 105-125.

Pinker, S. (1994). The language instinct. New York: William Marrow and Company Inc. http://dx.doi.org/10.1037/e412952005-009

Sapir, E. (1921). Language: An introduction of the study of speech. New York: Harcourt, Brace.

Slobin, D. (1996). From "thought and language" to "thinking for speaking." In J. Gumperz \& S. Levinson (Eds.), Rethinking linguistic relativity (pp. 70-96). Cambridge, MA: Cambridge University Press.

Slobin, D. (2005). Thinking for Speaking. Retrieved from http://ihd.berkeley.edu/Slobin.../(2005)\%20S

Treffers-Daller, J. (2012) Thinking for speaking and linguistic relativity among bilinguals: towards a new research agenda. Language, Interaction and Acquisition, 3(2), 288-300. http://dx.doi.org/10.1075/lia.3.2.06tre

Warschuaer, M., \& Kern, R. (2000). Introduction: Theory and practice of network-based language teaching. In M. Warchuaer \& R. Kern (Eds.), Network-based language teaching: Concepts and practice (pp. 1-10). Cambridge: Cambridge University Press. http://dx.doi.org/10.1017/CBO9781139524735

Whorf, B. L. (1956). A linguistic consideration of thinking in primitive communities. In J. B. Carroll (Ed.), Language, thought, and reality: Selected writings of Benjamin Lee Whorf (pp. 65-86). Cambridge: The MIT Press.

Williams, M., \& Burden, R. L. (1997). Psychology for language teachers: A social constructivist approach. Cambridge: Cambridge University Press.

Wintergerst, A. C., \& McVeigh, J. (2011). Tips for teaching culture: practical approaches to intercultural communication. New York: Pearson Education, Inc.

Wolfson, N. (1989). Perspectives: Sociolinguistics and TESOL. New York: Newbury House.

Wolfson, N., D'Amico-Reisner, L., \& Huber, L. (1983). How to arrange for social commitments in American English: The invitation. In N. Wolfson \& E. Judd (Eds.), Sociolinguistics and language acquisition (pp. 116-128). Rowley, MA: Newbury House. 